\title{
BMJ Open Uncovering social and psychosocial health factors through participatory qualitative research with low-income adults in a suburb of Montreal, Quebec
}

\author{
Caroline H-Y Wang (D) , ${ }^{1,2}$ Christine Loignon, ${ }^{1,2,3}$ Catherine Hudon ${ }^{1,3,4}$
}

To cite: Wang $\mathrm{CH}-\mathrm{Y}$, Loignon C, Hudon C. Uncovering social and psychosocial health factors through participatory qualitative research with lowincome adults in a suburb of Montreal, Quebec. BMJ Open 2020;10:e030193. doi:10.1136/ bmjopen-2019-030193

- Prepublication history for this paper is available online. To view these files, please visit the journal online (http://dx.doi. org/10.1136/bmjopen-2019030193).

Received 03 March 2019 Revised 09 January 2020 Accepted 15 January 2020

\section{Check for updates}

(C) Author(s) (or their employer(s)) 2020. Re-use permitted under CC BY-NC. No commercial re-use. See rights and permissions. Published by BMJ.

For numbered affiliations see end of article.

\section{Correspondence to} Caroline H-Y Wang; caroline.hy.wang@usherbrooke. ca

\section{ABSTRACT}

Objectives The association between social status and health is well established, but the psychosocial factors and mechanisms underlying this association are not fully understood. This study aims to identify and describe social and psychosocial factors that may harm the health of lowincome adults.

Design Participatory qualitative research using a problem-posing method based on Freire's pedagogy.

Setting Community organisation in a low-income district in the metropolitan area of Montreal, in the province of Quebec, Canada.

Participants Eight low-income adults using food bank services provided by the community organisation. Participants had to reside in the community organisation's service area, have insufficient income to cover living expenses, be aged 18 years or older, and be able to participate in group sessions.

Methods Eight weekly group sessions (average of 2.5 hours per session) were held using problem-posing method, which included activities such as presentation of representative stories or images and role-playing. Five additional sessions were held for thematic data analysis with participants.

Results A main factor identified as harming the health of participants was the dissonance between perceived current circumstances and the ideal of circumstances conceived early in life. This dissonance follows a loss or a failure to achieve the ideal of circumstances and generates profound malaise. Other main factors identified were the current circumstances as a social trap and the lack of love and support from an early age.

Conclusions This study identifies a new psychosocial factor, namely, the dissonance between perceived current circumstances and the ideal of circumstances conceived early in life. Larger studies should examine the influence of this factor on health.

\section{INTRODUCTION}

The association between social status and health is well established. ${ }^{2}$ This association forms a gradient that has been observed for many years and for many countries, including developed/industrialised countries: the lower the level of income, education or occupation, the higher the rate or risk

\section{Strengths and limitations of this study}

- The participatory research approach and the problem-posing method based on Freire's pedagogy allowed a deeper examination of factors that may harm the health of low-income adults and contribution of participants in the research project.

- Small group size and partnership quality with the community organisation assured participatory and ethical validity.

- Transferability of the results is limited, but this study allowed a contextual validity (the extent to which the research relates to the local situation), which is one of the strengths of participatory research.

of mortality or morbidity. ${ }^{13}$ For example, in Canada, mortality rate, incidence rate of pulmonary cancer and risk of psychological distress increased when the level of income, education or occupation decreased, for periods between 1991 and 2007. ${ }^{5-7}$ Understanding this association is of great interest but remains a puzzle, with many explanations and factors involved. ${ }^{289}$ Health behaviours explain part but not all of the association. ${ }^{810}$ Material conditions, such as quality of housing and working conditions and sufficiency or safety of food or water, may explain mortality decrease over time, but may not explain the gradient association still observed in developed/industrialised countries where basic material needs are fulfilled for the majority. ${ }^{811}$ How people perceive and experience their circumstances may influence their health, through a physiological response to psychological 'stressors'. ${ }^{1-14}$

Psychosocial factors are psychological phenomena potentially linked to the social environment and to pathophysiological changes. $^{15}$ Stress (perceived stress, life events) has been associated with social status and health, but its mediating role in the association between social status and health has 
been poorly supported by studies compared with the mediating role of control (job control, locus of control, control beliefs) ${ }^{16}$ Psychosocial factors at work, such as job strain (high demands and low control) and effort-reward imbalance (high workload and low payback), have been associated with the incidence of coronary heart disease. ${ }^{17}$ Lack of social support or integration, either perceived or actual, has been associated with higher risk of mortality and morbidity. ${ }^{18}{ }^{19}$ Social status may influence health through a combination of social support and other psychosocial factors. For example, low social status (level of education) may increase the risk of metabolic syndrome in women, through a pathway from low social status to an aggregate of low social support, self-esteem and optimism to high negative emotions to metabolic syndrome. ${ }^{20}$ Social support may also moderate the negative influence of stressors on health, by providing resources (emotional, informational or tangible) that influence behavioural or physiological responses to stressors. ${ }^{18}{ }^{21}$ In addition, feelings of being rejected or evaluated by others or negative self-evaluation by comparison with others activated the same neural regions as those associated with physical pain. ${ }^{22}$ Some authors have advanced that evaluation by others is a threat to self-esteem and that comparison with others could lead to self-image concern, feeling of inferiority and shame, anxiety and a physiological response. ${ }^{23}$ Lastly, early negative social experiences, such as neglect and emotional and physical abuse, have been associated with later health problems, ${ }^{24}{ }^{25}$ and low social status in childhood (level of parental education) may influence adult health through a pathway including negative social experiences in childhood and psychosocial factors in adult age (depression, anger, hostility, negative social contacts). ${ }^{26}$

Overall, psychosocial factors and mechanisms underlying the association between social circumstances and health are not fully understood. ${ }^{1816}$ Studies investigating psychosocial experiences are needed in complement to epidemiological studies. ${ }^{16}$ This is especially true for people experiencing poverty and social exclusion, which are human rights concerns. ${ }^{27}$ Participatory and qualitative research, by allowing examination of people's experiences and perceptions, ${ }^{28-30}$ has potential to provide a deeper understanding of factors influencing health. Previous participatory and qualitative studies with lowincome adults identified and described social factors extensively, but psychosocial factors and early experiences received less attention. ${ }^{31-41}$ The main social and psychosocial factors identified in these studies were lack of social relationships of quality, lack of money and related material and social conditions, stress, depression and low selfesteem. Examining both social and psychosocial factors with low-income adults may provide insights leading to better understanding of the association between social circumstances and health. This study aims to identify and describe factors, especially social and psychosocial factors, that may harm the health of low-income adults. In this study, the terms social factors and social circumstances are used equivalently, and encompass social status as well as working and living conditions and social relationships. ${ }^{942}$

\section{METHOD}

This study used a participatory research approach and a problem-posing method based on Freire's pedagogy, in order to allow a deeper understanding of people's circumstances and perceptions by including their participation in research, action and education. ${ }^{2943-47}$ Freire's pedagogy is a critical method of education, which seeks to transform social circumstances through discussion (dialogue), reflection and action (praxis), and critical consciousness (conscientisation) of the people. ${ }^{445}$ The problem-posing method aims to foster an understanding of people's circumstances by collectively examining elements-such as words or pictures-related to their circumstances or by using any other means that could bring an understanding about people's circumstances. ${ }^{4-46}$

\section{Setting}

This study was carried out in collaboration with a local community organisation that provides food bank, recreation and social support services to community members, especially people living in poverty, new immigrants and older adults. The community organisation is located in a district of Longueuil, a suburb city of Montreal, in the province of Quebec, Canada. This district has a high prevalence of low-income adults aged between 18 and 64 (19.8\% compared with $17.6 \%$ in the metropolitan area of Montreal, $16.0 \%$ in Quebec and $14.4 \%$ in Canada). ${ }^{48}$ In Quebec and Canada, low income is more common among Aboriginals, women, single parents, visible minorities, new immigrants, people living alone, people with reduced mobility and people receiving financial assistance. ${ }^{38}{ }^{49}$ In Quebec and Canada, about $2 \%$ of the population use food bank services, and among users of these services, $65 \%$ receive financial assistance and $45 \%$ live alone. ${ }^{5051}$

Recruitment of participants and group sessions with participants took place at the community organisation's facilities. Travel reimbursement was offered, childcare was possible and a psychosocial worker from the community organisation was available, if participants needed these. Coffee, snacks and sometimes lunch were provided during group sessions.

\section{Patient and public involvement}

The community organisation and the participants were not involved in the study design but were involved in methodological decisions. Two community workers from the community organisation were also involved in the recruitment of participants. The participants were also involved in determining research aims, collecting and analysing data, and presenting results. The first author organised and facilitated the research process.

Research questions were initially developed by the research team, then discussed with community members 
at an interactive information session that was held during recruitment of participants, and then further discussed with the participants at the beginning of data collection. Through that process, the research question was simplified and clarified, producing the research question that guided data collection and data analysis: "What harms our health?"

Methodological and ethical questions, such as recruitment of participants, accommodations for participants and confidentiality, were initially discussed with the community organisation's director and two community workers. Decisions from these discussions were included in the study protocol. Those questions were further discussed with the participants at the beginning of data collection. For example, the facilitator gave to the participants an initial list of roles and rights that was updated following the discussion with the participants. The facilitator also gave to the participants an initial questionnaire of participant characteristics that was revised with participants who shared their concerns and preferences. The participants and facilitator decided the frequency, number and duration of group sessions of data collection. The number and duration of these sessions were determined based on the feeling that what had to be discussed had been discussed.

The participants were involved in data collection and data analysis, as described in the following sections. Themes were developed and informed by participants' experiences and preferences through discussion with the participants and by discussing initial ideas and results with the participants throughout the research process. Through that process, the participants clarified and renamed themes. Participants' experiences from participating in the project were discussed during the group sessions of data collection. A detailed account of participants' positive, negative and self-discovery experiences from their involvement in the project is contained elsewhere. $^{41}$

Results were presented at a meeting of the community organisation's directors, by one participant and the facilitator. Prior to the presentation, two participants and the facilitator met to prepare it. The facilitator brought initial content and the two participants added and modified points, renamed themes and selected content to present. Conclusions and recommendations were determined by the two participants and the facilitator. Copies of the presentation were given to the directors and to all participants of the study and posted publicly on the community organisation's bulletin board. A copy of the final report (the first author's master's thesis) was given to the community organisation's director, and the facilitator contacted each participant to let them know that the final report was available.

\section{Participants}

Participants had to meet the food bank services' criteria, that is, reside in the community organisation's service area and have insufficient income to cover living expenses, be aged 18 years or older and be able to participate in group sessions. Full-time post-secondary students and retired persons receiving pension were not eligible.

A group of 6 to 10 persons was considered adequate, to foster multiple perspectives while allowing people to express themselves. ${ }^{52}$ The research team aimed to recruit 10 to 15 persons. Ten persons were recruited, and two of them abandoned before the second session of data collection for not being available or for being concerned about others' judgement.

Recruitment of participants was carried out from July to September 2014. To solicit involvement from community members, the first author and two community workers put up posters, distributed flyers, and talked with community members attending food bank services and cooking workshops. In addition, an interactive information session was held to discuss the research project and aims with community members. Community members interested in participating were met individually to determine eligibility and obtain informed consent.

\section{Data collection}

Eight weekly group sessions, with an average of five to six participants per session, were held from September to November 2014. The sessions lasted an average of 2.5 hours and were audio-recorded with participants' consent. At first, the facilitator invited everyone to introduce themselves and to ask questions following each presentation. Then, research and methodological questions were discussed, as described previously.

From the second session to the seventh, three activities were carried out with the problem-posing method. The participants and facilitator sat in a circle around a low table to foster in-depth discussion. The facilitator suggested the activities but did not have a list of themes to discuss. The facilitator invited participants to intervene without awaiting the facilitator's approval. Both the participants and facilitator asked questions to deepen or clarify what was said. The participants also commented what was said with additional experiences and perceptions.

1. For sessions 2 to 4 , the facilitator invited participants to bring and present something (eg, object, image, story) that represented what harms their health.

2. At sessions 5 and 6 , the facilitator invited participants to present in less than $1 \mathrm{~min}$ what is most harmful to their health. The facilitator timed the presentations.

3. At the seventh session, the facilitator invited participants to use role-playing to present issues they face and ways to resolve these.

At the eighth session, the facilitator invited participants to discuss the end of the group sessions and their experiences through these sessions. Following each group session, the facilitator took field notes, ${ }^{53}$ which informed debriefing sessions ${ }^{30}$ as well as the following group sessions and activities. More information about data collection and data analysis is available elsewhere. ${ }^{41}$ 


\section{Data analysis}

Thematic analysis was used to identify representative themes with participants. ${ }^{5455}$ Following each group session of data collection, the facilitator listened to the audio recording, noted initial ideas and transcribed the audio recording verbatim using ethnographic methods. ${ }^{5657}$ To protect confidentiality, names were replaced by codes in transcripts. The facilitator discussed initial ideas with participants at the fifth, sixth and seventh sessions of data collection.

Following data collection, six of the participants engaged in the data analysis, which included five group sessions held between November 2014 and February 2015. Prior to these sessions, the participants and facilitator individually read parts of five of the eight transcripts and identified excerpts and codes, which were discussed during the group sessions. Excerpts were sentences or paragraphs about what harms the health of participants. Codes identified what was said explicitly (using the participants' exact words) or implicitly (inferring from what the participants said). The facilitator developed a list of codes organised into groups, which were derived from questions discussed during data collection, the codes themselves, and literature on social determinants of health and psychosocial factors. ${ }^{916}$ The list of codes and groups was reviewed by the authors and discussed with the participants at the second and fourth sessions of data analysis.

The facilitator refined the list of codes and groups while systematically coding the eight transcripts using qualitative data analysis software (ATLAS.ti V.1.0 for Mac). From the refined list of codes and groups, the authors developed representative themes, which the facilitator reviewed using disconfirming data, excerpts, the transcripts as a whole and field notes. ${ }^{30} 54$ The facilitator also examined codes by participant and by certain characteristics, such as reporting mental health problems and living alone. The facilitator wrote a report, including themes, descriptions, excerpts, interpretations and conclusions, which was reviewed by the authors and discussed with five participants during a group session held in September 2015.

\section{RESULTS}

The participants were five women and three men, aged 44 to 63 years, who had completed at least high school education and had an annual income under \$C15000 (table 1). All participants were using food bank services provided by the community organisation, and all participants reported at least one physical health problem. Half of the participants reported mental health problems ('mentalhealth participants'), while two other participants had reduced mobility. The mental-health participants reported Québécois origins and presented themselves as former professionals. The participants with reduced mobility reported Québécois or Aboriginal origins. The mental-health participants and participants with reduced mobility were receiving last-resort financial assistance.

\begin{tabular}{|c|c|}
\hline Characteristic & $\begin{array}{l}\text { Participants } \\
(n=8)\end{array}$ \\
\hline \multicolumn{2}{|l|}{ Gender } \\
\hline Women & 5 \\
\hline Men & 3 \\
\hline \multicolumn{2}{|l|}{ Age } \\
\hline $40-49$ & 3 \\
\hline $50-59$ & 4 \\
\hline $60-69$ & 1 \\
\hline \multicolumn{2}{|l|}{ Ethnicity } \\
\hline Québécois & 5 \\
\hline Aboriginal & 2 \\
\hline Latin American & 1 \\
\hline \multicolumn{2}{|l|}{ Education } \\
\hline University & 3 \\
\hline College & 3 \\
\hline High school & 2 \\
\hline \multicolumn{2}{|l|}{ Main source of income } \\
\hline Financial assistance & 6 \\
\hline Part-time work & 1 \\
\hline Other & 1 \\
\hline \multicolumn{2}{|l|}{ Household } \\
\hline Alone, no children & 5 \\
\hline Alone, children & 1 \\
\hline Couple, children & 1 \\
\hline Family, children & 1 \\
\hline
\end{tabular}

Children=children and grandchildren.

The participants who reported Québécois origins $(n=5)$ were living alone and had no children. The participants who reported Aboriginal ( $n=2)$ or Latin American $(n=1)$ origins had both children and grandchildren, and were living in a couple or a family, or living alone.

Three main factors were identified as harming the health of participants. The factor for which profound malaise was expressed was the dissonance between perceived current circumstances and the ideal of circumstances conceived early in life ('dissonance between circumstances and ideal'). This factor was related to the other factors, which were the current circumstances as a social trap and the lack of love and support from an early age (figure 1). The list of codes and groups of factors reported as harming the health of participants is available elsewhere. ${ }^{41}$ All quotes reported here are translated from French.

\section{Dissonance between circumstances and ideal}

The mental-health participants and participants with reduced mobility reported a gap between their current circumstances and their former or ideal circumstances, 


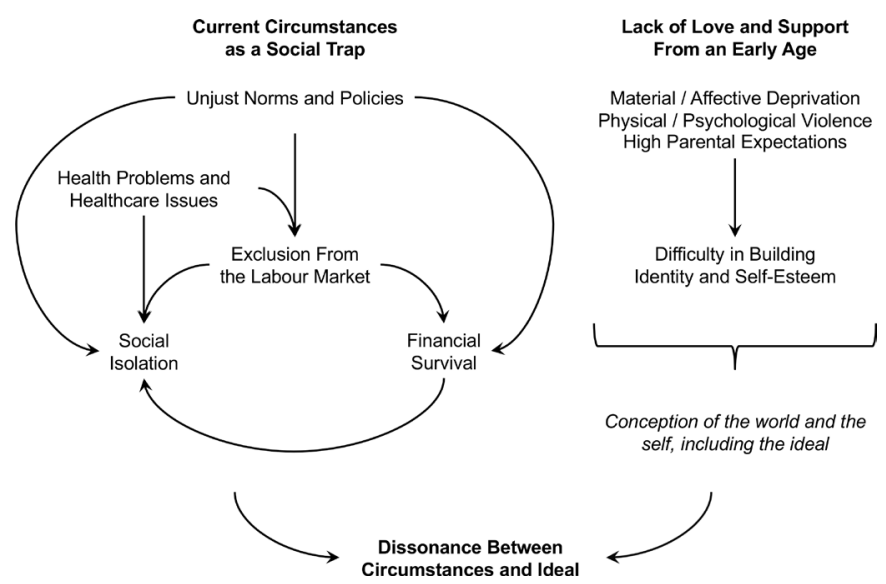

Figure 1 Three main themes (bold text) and sub-themes (regular text) of social and psychosocial factors reported by participants as harming their health. Dissonance between circumstances and ideal=dissonance between perceived current circumstances and the ideal of circumstances conceived early in life. The ideal is understood as being part of one's conception of the world and the self, formed through early-life social interactions. As early-life social interactions may influence the formation of the ideal, experiences of lack of love and support may influence the formation of the ideal. For example, parental expectations could be integrated in one's ideal from an early age. The difficulty to achieve this ideal may lead to dissonance.

which affected identity, self-esteem and well-being. They expressed profound malaise from losing or being excluded from work and from other social circumstances. The mental-health participants were experiencing this currently, whereas the participants with reduced mobility experienced this previously.

One mental-health participant reported her downfall from her work position and from being a highperformance athlete: "So when I fell, I fell from high. And it's as if I have the same perception as 15 years ago-I should still be there [at the top]". Another mental-health participant said: "When I start thinking about my situation, the real situation of being below-below the poverty line! I get down on myself. There's nothing joyful about the situation that I'm in. Sick, poor, underprivileged, alone, no friendships-honestly, this is down. This is very, very down". Many participants reported discomfort with people they knew formerly, as they could no longer join social activities or share common concerns and topics of conversation. One mental-health participant said: "It's also the social side of things, you know, that maybe is also harming our health. I'm less inclined to go out or meet people who had, let's say, the same social standing as me. I put up a barrier between myself and my former friends, when I fell. And I'm the one who created distance because I wasn't well. I wasn't comfortable in my own skin anymore, with them. They were all workers_- 'professionals' you could say".

The participants reported that losing their circumstances affected their identity, and that they negatively judged themselves, which increased their malaise. One mental-health participant said regarding the loss of her work position: "Anyway, at that point in time I lost a lot—and it might have been my ego too, I don't know". One participant with reduced mobility said: "I started from a profession that I love with all my heart, and I find myself with nothing... I started to lose everything-identity... I started to search for who I was. I'm nothing anymore. I'm nothing anymore, I'm a zero now. I considered myself to be a less than nothing, as though I was living off of others". Most mental-health participants also said that judgement or rejection by others, whether perceived or actual, reinforced their self-judgement and malaise: "It's as if my value comes from how other people see me... So if I think that you're judging me, then I really feel like a loser".

\section{Current circumstances as a social trap}

The participants reported constraining and stressful experiences due to their current social and health circumstances, which were harmful to their health and perpetuated their situation. Five interrelated sub-themes were identified: (1) exclusion from the labour market, (2) financial survival, (3) social isolation, (4) health problems and healthcare issues, and (5) unjust norms and policies (figure 1).

Exclusion from the labour market. The mental-health participants and participants with reduced mobility reported being excluded from the labour market, but only the mental-health participants reported this exclusion as currently harming their health. The mental-health participants reported that they were struggling to find working conditions that accommodated their needssuch as a tendency to over-perform, limited endurance and a desire for collaboration rather than competitionbut that they would like to work or otherwise contribute to society. One of them said: "I prefer to work for a longer time, but at my own rhythm. I need to be able to work at my own rhythm-otherwise, if it's always moving so quickly, I just can't do it. And yet, I'm a very efficient person. On a short time frame, if there's a rush or something, then I can do it, but not all the time, it's impossible. I can't. There's my mental health". This participant also said: "The work environment is really competitive, you know? And that gets difficult, because if you're not able to play the game, you're out! If you play the game, you wear yourself out-myself, anyway, as a hyper-sensitive person, I completely wear myself out". The mental-health participants also reported being afraid of repeating former work experiences and doubting their capacities. One of them said: "But it's hard to find your self-confidence, to present yourself to employers—and, am I going to fall back into the same patterns, and have a burnout". Another said: "[Fear] makes you sick, it prevents you from returning to work. It completely perturbs you”.

Financial survival. The mental-health participants reported lack of money, resulting from their exclusion from the labour market, as being a source of stress and anxiety and leading to their social isolation. They reported being forced to choose between basic essentials, struggling to make ends meet and not being able to satisfy their needs-such as a specific diet, social activities, psychological services, housing and transport. One of them recounted: "Now I have to move-it's extremely stressful. I'm completely destabilized, unbalanced, at the moment. Because 
finding an apartment at a price that's reasonable for me is practically impossible, so now I see myself living in a hole and falling back into survival mode: no more money, no more activities, so I see even fewer friends".

Social isolation. The participants living alone reported that being with others or being alone was a source of stress and unease, and that this was an important issue for their health. They reported not being able to express who they are, what they are living and how they feel, as others either were not available or could not understand their circumstances due to a lack of experience or knowledge. One participant said that her cancer was due to: "The suffering inside that hasn't been expressed, and not listened to-every time I tried to talk about my problems I was told, 'oh, I don't have time". The participants living alone said that having to keep things inside was destructive and that having to be careful around others to avoid lack of understanding and negative attitudes was stressful and energy consuming. One mental-health participant said: "You know, when you have a label on you, when there's something about you that you're rejected automatically... if they put their finger on the problem... it causes you to be on edge, because you try to hide it. And you become really on edge. And that is completely draining". Some participants living alone reported former experiences of being judged, rejected, diminished, stigmatized, or discriminated against by others because of their circumstances, and that these experiences were hurtful and stressful. The participants living alone reported isolating themselves to avoid stress and unease from being with others, and that this isolation was also an issue. One participant said: "I isolated myself because of stress, because it really made me sick. Isolation-it's a problem - so I am stuck in a vicious cycle, at the end of the day". Another recounted: "Interpersonal relationships are difficult for me too... This morning I was alone, and I really wasn't doing well. Because I was talking to myself, saying, "how can I solve my problems? I don't see the answer'... But then I come [here, to the community organization] and people are making food, eating, making calls... and I'm just like [sound of being overwhelmed]".

Health problems and healthcare issues. Most participants reported their health problems and healthcare issues as negatively affecting their physical, biological or social functioning and as contributing to their exclusion from the labour market and their social isolation. Regarding healthcare, many participants reported issues with their medications, especially side effects and inadequate follow-up by their medical team: "There are drugs that paralyze you, so that even if you want to go on the labor market, [it is not possible]". Many participants also reported healthcare service limitations, such as lack of access to public psychological services and long waiting times for diagnosis, which impeded their recovery from health problems: "And I was in despair... I didn't have the tools, I didn't have the means. And it was not accessible, because it's relatively new, this diagnosis... But now, I'm able to identify it. And that was a huge progress in my life".

Unjust norms and policies. Many participants reported that unjust social norms and policies, which led to and perpetuated their social circumstances, were harmful to their health. They reported social norms that shaped others' attitudes and led to a lack of understanding and acceptance of their circumstances and differences by others. Some of the mental-health participants said that this pushed them to conform rather than to be themselves, which contributed to their health problems: "I'm different, so I want my differences to be taken into account so that I can exist. Because if not, nothing's possible - I felt sick from wanting to be like everybody else". The mental-health participants also reported inadequate public and employment policies, which prevented them from entering the labour market and kept them in a situation of perpetual lack of money: "We don't have the right to be sick in our society. I feel I don't have the right to live that out and to make that journey, in any way at all, because if you do that, man, you won't work. And you won't be able to work and, if you don't work, well you have $\$ 927$ per month and try to sort this out on your own".

\section{Lack of love and support from an early age}

Most participants reported adverse experiences starting early in life, which marked them for life, were stressful and led to health problems. They reported parents who could not provide for them materially or affectively, and physical or psychological violence, such as being beaten or not being valued. They emphasised the lack of affection and support, the feeling of being rejected and abandoned, and the difficulty in building identity and self-esteem.

The mental-health participants did not report material deprivation and physical violence but did report affective deprivation and psychological violence. They also reported parents with high expectations, including high expectations of their social status: "It's a family of intellectuals—super intellectuals—and I was the little musician, and music, it's idiotic". The mental-health participants reported current consequences resulting from these experiences: "It's as though [the things that were missing in childhood] affects all aspects of life: interpersonal relationships, choices, how to define yourself, to know what you want, what you like, what you don't like". They reported a tendency to overgive and overperform to seek love and value, but that they never achieved this and therefore exhausted themselves: "I really over did it, but, you know, that hides a lot of things as well. The lack of approval from family... you know, dada-dada-dada. I needed to prove to myself that I was capable".

The other participants who reported adverse experiences starting early in life recounted how they overcame these experiences: by developing "a strong character", which could be understood as being emotionally strong so as not to be affected by violence against them; by confronting their parents in a way that gave them more control in their relationships with their parents; and by raising their children differently than they had been raised: "My father was always on my case- he beat me, there was always something — and I said to myself, 'I'll never do that with my kids'. Instead, I'll sit down with them, and say 'you can choose what you want to do'. So for me, by doing that, it was like [sigh of relief]". 


\section{DISCUSSION}

This study identifies a new psychosocial factor, namely, the dissonance between perceived current circumstances and the ideal of circumstances conceived early in life ('dissonance between circumstances and ideal'). This dissonance, which represents a gap between current circumstances and former or ideal circumstances, explains the profound malaise experienced by participants. The circumstances included social circumstances (social status, labour market, money, social relationships) and health status. We understand the ideal as being part of one's conception (opinion or image) of the self and the world, which conception is formed through social interactions early in life and determines one's attitude (way of being) in the world. ${ }^{58} 59$ Thus, the ideal is part of identity, and the dissonance that follows the loss or failure to achieve an ideal of circumstances disturbs the sense of identity and generates profound malaise. This dissonance may add to other factors such as daily struggles: if two lowincome people experience similar social circumstances, the one who experiences greater dissonance may suffer more. To our knowledge, this factor has not been empirically identified previously. Thus, we discuss further this factor and its novelty.

The dissonance between circumstances and ideal differs from other psychological theories. It is more specific than cognitive dissonance, which represents a gap between two cognitive components, where each component includes "any knowledge, opinion, or belief about the environment, about oneself, or about one's behavior" (p. 3). ${ }^{6061}$ The dissonance between circumstances and ideal represents a gap between two cognitive components, where the two components relate specifically to one's circumstances and one's ideal of circumstances, and not one's behaviour. The dissonance between circumstances and ideal is also more specific than perceptual control theory, which is a model based on negative feedback control where perception is compared with a desired state and if there is discrepancy, a behaviour is done in order for the perception to match the desired state. ${ }^{62}$ The dissonance between circumstances and ideal is conceptually nearer to personenvironment fit theories, ${ }^{63}$ but specifies that the 'fit' is between perceived whole circumstances, including health status, and the ideal of circumstances, and does not refer solely to the work environment as many person-environment fit theories do. ${ }^{6364}$

The dissonance between circumstances and ideal also differs from other psychosocial factors. It involves perception and conception of one's whole circumstances, not only one particular circumstance such as lack of control at work and perceived lack of support. It involves evaluation of one's own circumstances compared with one's ideal of circumstances, and not a perception of the evaluation by others of one's circumstances or an evaluation of one's circumstances by comparing with others' circumstances, as advanced by some authors. ${ }^{23}$ However, the profound malaise related to the dissonance could be aggravated by evaluation by others and comparing with others. The dissonance between circumstances and ideal is supported in part by results from meta-analyses of cross-sectional studies that showed that psychological distress among unemployed people was associated with high work-role centrality and high desire for work, a level of desire incongruent with being unemployed. ${ }^{656}$ In addition, rumination has been found to mediate the association between negative life events and anxiety/depression. ${ }^{67}$ Rumination could be seen as not accepting the current circumstances, and in that sense, could support the concept of dissonance. In the present study, acceptance of the circumstances was a strategy reported by participants to live and feel better (data reported elsewhere ${ }^{41}$ ), and this strategy may explain why participants with reduced mobility did not express current profound malaise as the mental-health participants did.

The dissonance between circumstances and ideal builds on Tarlov's proposal of a mechanism through which social circumstances influence health. Tarlov ${ }^{68}$ wrote: "When expectations and reality clash, we speculate, the chronic, persistent, inescapable dissonance between what a person would like to do or become and what seems accomplishable triggers biological signals that are antecedent of chronic disease development". (p. 85) While Tarlov suggested that expectations and reality come from observation and experience of social inequalities, the dissonance between circumstances and ideal is not limited to social inequalities and involves the perception and conception of one's whole circumstances. In addition, while Tarlov did not provide evidence for his proposal, the present study identified dissonance between circumstances and ideal from data collected through group sessions with participants. The notion of identity has not been widely discussed in the social determinants of health and health inequality literature, but for some authors, it may explain the persistence of health inequality. ${ }^{8}$ Previous participatory and qualitative studies with low-income adults have not identified the dissonance identified in the present study, although some of these studies identified factors that could suggest a dissonance between circumstances and ideal, such as failures, frustrations and regret. ${ }^{32} 3869$ The dissonance between circumstances and ideal may have been identified in the present study due to the inclusion of participants self-identifying as former professionals, although the finding was also supported by other participants who lost or failed to achieve an ideal of circumstances (ie, participants with reduced mobility).

The present study also identifies the experience of having parents with high expectations regarding social status as harming the health of participants, in addition to other early social experiences identified in previous studies, such as neglect and emotional and physical abuse. ${ }^{24} 2537$ This experience, combined with experiences of affective deprivation and psychological violence, could contribute to dissonance between circumstances and ideal: on the one hand, parental expectations could be integrated in one's ideal from an early age; on the other hand, one could have difficulty achieving this ideal 
because of the consequences of lack of love and support (ie, low self-identity, low self-esteem, tendency to overgive or overperform, as reported in this study), which can limit functioning on the labour market and in social relationships. This experience may be more common in middle-class families, as participants who reported this experience did not report material deprivation in childhood. The participants who did not report having parents with high expectations overcame negative early social experiences by being emotionally strong, taking control in their relationship with their parents, or raising their children differently, suggesting that these participants were able to define themselves independently of the influence of the adults at the origin of those experiences. Self-definition, independently of the influence of adults, may be more difficult to achieve when one experiences having parents with high expectations, in addition to parents being absent or violent, compared with when one experiences solely these latter experiences.

The present study confirms several social factors identified in previous studies, including experiences related to lack of love and support from an early age, social isolation, exclusion from the labour market and financial survival. ${ }^{24} 2531-40$ Factors grouped under the theme of current circumstances as a social trap are consistent with literature on social determinants of health. ${ }^{29} 70$ The present study shows that these factors lead to social isolation (figure 1) and, as reported in previous participatory and qualitative studies, ${ }^{39} 6971$ keep people in poverty and social exclusion. In the present study, these interrelated factors also prevent people from achieving their ideal of circumstances and can indirectly influence the formation of the ideal: for example, valorisation in society of a particular social circumstance, such as a professional social status, can influence social interactions, which influence the formation of the ideal.

The participatory research approach and the problemposing method based on Freire's pedagogy allowed a deeper examination of factors that may harm the health of low-income adults and contribution of participants in the research project. Although factors have been reported by participants as harming their health, a causal relationship cannot be established due to the study design. The small group size allowed participants to express themselves in more depth, although some topics might not have been discussed fully (eg, current consumption of alcohol and drugs because of reluctance to discuss this topic). The small number of participants limits transferability of the results, such that results from sub-analyses from this study are transferable to groups of people with similar characteristics or experiences. Despite this, the participants had various characteristics commonly found among lowincome people in Quebec and Canada, including Aboriginals, women, single parents, people living alone, people with reduced mobility and people receiving financial assistance ${ }^{3849}$; this variety of characteristics allowed a range of experiences to be covered. Participation was limited by the short duration of the study, that is, 2 months for data collection and 4 months for data analysis, whereas other participatory studies lasted 6 months to 4 years. ${ }^{41}$

Further research is needed to identify and measure the dissonance between circumstances and ideal, and to examine the influence of this factor in the association between social circumstances and health. Future research could examine this factor among larger groups and among other populations (eg, middle-class workers, former professionals and people with reduced mobility, with and without mental health problems). In clinical practice, health professionals can consider dissonance between circumstances and ideal in people experiencing profound malaise and accompany them in order to understand, together with the patient, their ideal of circumstances in relation to their perceived current circumstances. Given the influence of early social experiences in the formation of the ideal and in social functioning throughout life, policies should seek to enable caregivers and other adults responsible for children to respond to children's needs for love and support.

\section{Author affiliations}

${ }^{1}$ Faculté de médecine et des sciences de la santé, Université de Sherbrooke, Sherbrooke, Quebec, Canada

${ }^{2}$ Centre de recherche Charles-Le Moyne-Saguenay-Lac-Saint-Jean sur les innovations en santé, Centre intégré de santé et de services sociaux de la Montérégie-Centre, Longueuil, Quebec, Canada

${ }^{3}$ Département de médecine de famille et de médecine d'urgence, Université de Sherbrooke, Sherbrooke, Quebec, Canada

${ }^{4}$ Centre de recherche du Centre hospitalier universitaire de Sherbrooke, Sherbrooke, Quebec, Canada

Acknowledgements The authors thank all participants and the community organisation's directors and community workers for their time and involvement in the research project. The authors acknowledge the Unité de recherche clinique et épidémiologique du Centre de recherche du Centre hospitalier universitaire de Sherbrooke for assistance with editing and proofreading.

Contributors $\mathrm{CH}-\mathrm{YW}$ designed the research project, collected the data and drafted the manuscript. $\mathrm{CL}$ and $\mathrm{CH}$ supervised the work of $\mathrm{CH}-\mathrm{YW}$. CH-YW, $\mathrm{CL}$ and $\mathrm{CH}$ analysed and interpreted the data, revised the manuscript and approved the final version of the manuscript.

Funding $\mathrm{CH}-\mathrm{YW}$ received a Master's Award from the Canadian Institutes of Health Research and the Canadian Foundation for Dietetic Research (201302MIE-304577-235683).

Disclaimer The funders had no role in study design, data collection, analysis and interpretation, preparation of the manuscript and decision to publish.

Competing interests None declared.

Patient consent for publication Obtained.

Ethics approval The Research Ethics Board of Hôpital Charles-Le Moyne approved the study (AA-HCLM-14-012).

Provenance and peer review Not commissioned; externally peer reviewed.

Data availability statement No data are available.

Open access This is an open access article distributed in accordance with the Creative Commons Attribution Non Commercial (CC BY-NC 4.0) license, which permits others to distribute, remix, adapt, build upon this work noncommercially, and license their derivative works on different terms, provided the original work is properly cited, appropriate credit is given, any changes made indicated, and the use is non-commercial. See: http://creativecommons.org/ licenses/by-nc/4.0/.

ORCID iD

Caroline H-Y Wang http://orcid.org/0000-0002-3134-0580 


\section{REFERENCES}

1 Adler NE, Stewart J. Health disparities across the lifespan: meaning, methods, and mechanisms. Ann N Y Acad Sci 2010;1186:5-23.

2 Commission on Social Determinants of Health. Closing the gap in a generation: health equity through action on the social determinants of health. Final report of the Commission on Social Determinants of Health. World Health Organization, 2008. Available: https://www.who. int/social_determinants/thecommission/finalreport/en/ [Accessed 15 Feb 2019].

3 Stringhini S, Carmeli C, Jokela M, et al. Socioeconomic status and the $25 \times 25$ risk factors as determinants of premature mortality: a multicohort study and meta-analysis of 1.7 million men and women. Lancet 2017;389:1229-37.

4 Working Group on Inequalities in Health. Inequalities in health. Report of a research Working Group. Department of Health and Social Security, 1980. Available: http://www.sochealth.co.uk/nationalhealth-service/public-health-and-wellbeing/poverty-and-inequality/ the-black-report-1980 [Accessed 1 Dec 2019]

5 Mitra D, Shaw A, Tjepkema M, et al. Déterminants sociaux de l'incidence du cancer du poumon au Canada: une étude prospective sur 13 ans. Statistique Canada, 2015. Available: https://www150. statcan.gc.ca/n1/pub/82-003-x/2015006/article/14195-fra.pdf [Accessed 16 Feb 2019]

6 Orpana H, Lemyre L, Gravel R. Revenu et détresse psychologique: le rôle de l'environnement social. Statistique Canada, 2009. Available: https://www150.statcan.gc.ca/n1/pub/82-003-x/2009001/article/ 10772-fra.pdf [Accessed 16 Feb 2019].

7 Tjepkema M, Wilkins R, Long A. Mortalité par cause selon la suffisance du revenu au Canada: une étude de suivi sur 16 ans. Statistique Canada, 2013. Available: https://www150.statcan.gc.ca/ n1/pub/82-003-x/2013007/article/11852-fra.pdf [Accessed 16 Feb 2019].

8 Bartley M. Health inequality: an introduction to theories, concepts, and methods. Cambridge, United Kingdom: Polity Press, 2004.

9 Solar O, Irwin A. A conceptual framework for action on the social determinants of health. Social determinants of health discussion paper 2 (policy and practice). World Health Organization, 2010. Available: https://apps.who.int/iris/bitstream/handle/10665/44489/ 9789241500852_eng.pdf [Accessed 16 Feb 2019].

10 Marmot MG, Bosma H, Hemingway H, et al. Contribution of job control and other risk factors to social variations in coronary heart disease incidence. Lancet 1997;350:235-9.

11 Marmot MG, Sapolsky R. Of baboons and men: social circumstances, biology, and the social gradient in health. In Weinstein M, Lane MA, Committee on Population, Division of Behavioral and Social Sciences and Education, National Research Council, eds. Sociality, hierarchy, health: comparative biodemography: a collection of papers. Washington, DC: The National Academies Press, 2014: 365-88.

12 McEwen BS, Bowles NP, Gray JD, et al. Mechanisms of stress in the brain. Nat Neurosci 2015;18:1353-63.

13 Sapolsky RM. Stress and the brain: individual variability and the inverted-U. Nat Neurosci 2015;18:1344-6.

14 Seyle H. The stress of life. New York, NY: McGraw-Hill, 1978.

15 Hemingway H, Marmot M. Evidence based cardiology: psychosocial factors in the aetiology and prognosis of coronary heart disease: systematic review of prospective cohort studies. BMJ 1999;318:1460-7.

16 Matthews KA, Gallo LC, Taylor SE. Are psychosocial factors mediators of socioeconomic status and health connections? A progress report and blueprint for the future. Ann N Y Acad Sci 2010;1186:146-73.

17 Kuper $\mathrm{H}$, Marmot M, Hemingway $\mathrm{H}$. Systematic review of prospective cohort studies of psychosocial factors in the etiology and prognosis of coronary heart disease. Semin Vasc Med 2002;02:267-314.

18 Holt-Lunstad J, Smith TB, Layton JB. Social relationships and mortality risk: a meta-analytic review. PLoS Med 2010;7:e1000316.

19 Valtorta NK, Kanaan M, Gilbody S, et al. Loneliness and social isolation as risk factors for coronary heart disease and stroke: systematic review and meta-analysis of longitudinal observational studies. Heart 2016;102:1009-16.

20 Matthews KA, Räikkönen K, Gallo L, et al. Association between socioeconomic status and metabolic syndrome in women: testing the reserve capacity model. Health Psychol 2008;27:576-83.

21 Jewell SL, Luecken LJ, Gress-Smith J, et al. Economic stress and cortisol among postpartum low-income Mexican American women: buffering influence of family support. Behav Med 2015;41:138-44.

22 Eisenberger NI. The pain of social disconnection: examining the shared neural underpinnings of physical and social pain. Nat Rev Neurosci 2012;13:421-34.
23 Wilkinson RG, Pickett K. The spirit level: why greater equality makes societies stronger. New York, NY: Bloomsbury Press, 2011.

24 Anda RF, Felitti VJ, Bremner JD, et al. The enduring effects of abuse and related adverse experiences in childhood. A convergence of evidence from neurobiology and epidemiology. Eur Arch Psychiatry Clin Neurosci 2006;256:174-86.

25 Kreppner JM, Rutter M, Beckett C, et al. Normality and impairment following profound early institutional deprivation: a longitudinal follow-up into early adolescence. Dev Psychol 2007;43:931-46.

26 Lehman BJ, Taylor SE, Kiefe Cl, et al. Relation of childhood socioeconomic status and family environment to adult metabolic functioning in the CARDIA study. Psychosom Med 2005;67:846-54.

27 Alston P. Report of the special Rapporteur on extreme poverty and human rights (A/HRC/29/31). United Nations Human Rights Council, 2015. Available: https://www.ohchr.org/en/issues/poverty/pages/srex tremepovertyindex.aspx [Accessed 1 Dec 2019].

28 Creswell JW. Qualitative inquiry and research design: choosing among five approaches. 3rd edn. Thousand Oaks, CA: SAGE Publications, 2013.

29 Freire P. Creating alternative research methods: learning to do it by doing it. In: Hall B, Gillette A, Tandon R, eds. Creating knowledge: a monopoly? Participatory research in development. New Delhi, India: Society for Participatory Research in Asia, 1982: 29-37.

30 Lincoln YS, Guba EG, Pilotta JJ. Naturalistic inquiry. Beverly Hills, CA: SAGE Publications, 1985: 9. 438-9.

31 Collins SB. An understanding of poverty from those who are poor. Action Res 2005;3:9-31.

32 Baranowski KL. Health perceptions and barriers to health as defined by women marginalized by socioeconomic status. Doctoral dissertation, 1999. [Retrieved from ProQuest Dissertations and Theses Global database].

33 Bermúdez-Millán A, Damio G, Cruz J, et al. Stress and the social determinants of maternal health among Puerto Rican women: a CBPR approach. J Health Care Poor Underserved 2011;22:1315-30.

34 Chircop A. Environmental health inequities: low-income mothers' negotiation of health in a low-income urban neighborhood. Doctoral dissertation, 2010. [Retrieved from ProQuest Dissertations and Theses Global database].

35 Doornbos MM, Zandee GL, DeGroot J, et al. Using communitybased participatory research to explore social determinants of women's mental health and barriers to help-seeking in three urban, ethnically diverse, impoverished, and underserved communities. Arch Psychiatr Nurs 2013;27:278-84.

36 Kaplan SA, Madden VP, Mijanovich T, et al. The perception of stress and its impact on health in poor communities. J Community Health 2013;38:142-9.

37 McAll C, Awad J, Desgagnés J-Y, et al. Au-delà du préjugé: trajectoires de vie, pauvreté et santé. Québec, Canada: Presses de l'Université du Québec, 2012.

38 Raphael D. Poverty in Canada: implications for health and quality of life. Toronto, Canada: Canadian Scholars' Press, 2011.

39 Reid CJ. "We don't count, we're just not there": using feminist action research to explore the relationship between exclusion, poverty and women's health. Doctoral dissertation, 2002. [Retrieved from ProQuest Dissertations and Theses Global database].

40 Young L, Wharf Higgins J. Using participatory research to challenge the status quo for women's cardiovascular health. Nurs Inq 2010;17:346-58

41 Wang $\mathrm{CH}-\mathrm{Y}$. Une recherche participative sur les déterminants sociaux et psychosociaux de la santé avec des adultes ayant un faible revenu. Master's thesis, 2017. Available: http://hdl.handle.net/ 11143/11072 [Accessed 16 Feb 2019].

42 Graham H. Social determinants and their unequal distribution: clarifying policy understandings. Milbank Q 2004;82:101-24.

43 Brydon-Miller M, Kral M, Maguire P. Jazz and the banyan tree: roots and riffs on participatory action research. In: Denzin NK, Lincoln YS, eds. The SAGE Handbook of qualitative research. Thousand Oaks, CA: SAGE Publications, 2011: 387-400.

44 Freire P. L'éducation: pratique de la liberté. Paris, France: Éditions du Cerf, 1978.

45 Freire P. Pedagogy of the oppressed. New York, NY: Penguin Books, 1996.

46 Kamberelis G, Dimitriadis G. Focus groups: contingent articulations of pedagogy, politics, and inquiry. In: Denzin NK, Lincoln YS, eds. The SAGE Handbook of qualitative research. Thousand Oaks, CA: SAGE Publications, 2011: 545-61.

47 Park $P$. What is participatory research? A theoretical and methodological perspective. In: Park P, Brydon-Miller M, Hall B, eds. Voices of change: participatory research in the United States and Canada. Toronto, Canada: OISE Press, 1993: 1-19. 
48 Statistics Canada. National Household Survey (NHS) Profile (2011 NHS, No. 99-004-XWE). Statistics Canada, 2013. https://www12. statcan.gc.ca/nhs-enm/2011/dp-pd/prof/index.cfm?Lang=E

49 Fréchet $\mathrm{G}$, Lechaume A, Legris $\mathrm{R}$, et al. La pauvreté, les inégalités et l'exclusion sociale au Québec: état de situation 2013. Centre d'étude sur la pauvreté et l'exclusion, Gouvernement du Québec, 2014. Available: https://www.mtess.gouv.qc.ca/publications/pdf/CEPE Etat_Situation_2013.pdf [Accessed 2 Dec 2019].

50 Banques alimentaires Canada. Bilan-Faim 2015, 2015. Available: https://www.banquesalimentairescanada.ca

51 Statistics Canada. Estimations démographiques trimestrielles: janvier à mars 2015 (No. 91-002-X). Statistics Canada, 2015. https:// www150.statcan.gc.ca/n1/fr/pub/91-002-x/91-002-x2015001-fra. pdf?st=UoMPs7im

52 Fortin M-F. Fondements et étapes du processus de recherche: méthodes quantitatives et qualitatives. 2nd edn. Montréal, Canada: Chenelière Éducation, 2010.

53 Olmos JC, McQuiston C, Parrado EA. Field notes guide. In: Israel BA, Eng E, Schulz AJ, eds. Methods in community-based participatory research for health. San Francisco, CA: Jossey-Bass, 2005: 423-4.

54 Braun V, Clarke V. Using thematic analysis in psychology. Qual Res Psychol 2006;3:77-101.

55 Paillé P, Mucchielli A. L'analyse qualitative en sciences humaines et sociales. Paris, France: Armand Colin, 2012.

56 Centre for oral history and digital storytelling, producer. Interview transcription [Webinar], 2013. Available: http://storytelling.concordia. $\mathrm{ca} /$ content/webinar-2-interview-transcription [Accessed 15 Feb 2019].

57 Powers WR. Transcription techniques for the spoken word. Lanham, MD: AltaMira Press, 2005.

58 Adler A. Pratique et théorie de la psychologie individuelle comparée. Paris, France: Payot, 1961.

59 Adler A. Le sens de la vie: étude de psychologie individuelle. Paris, France: Payot, 2002

60 Festinger L. A theory of cognitive dissonance. Stanford, CA: Stanford University Press, 1962.
61 Metin I, Metin Camgoz S. The advances in the history of cognitive dissonance theory. Int J Humanit Soc Sci 2011;1:131-6.

62 Powers WT, Abbott B, Carey TA, et al. Perceptual control theory: a model for understanding the mechanisms and phenomena of control, 2011. Available: http://www.pctweb.org/PCTunderstanding-2.pdf [Accessed 2 Dec 2019].

63 Edwards JR, Caplan RD, Harrison RV. Person-environment fit theory: conceptual foundations, empirical evidence, and directions for future research. In: Cooper CL, ed. Theories of organizational stress. Oxford: Oxford University Press, 1998: 28-67.

64 Su R, Murdock C, Rounds J. Person-environment fit. In: Hartung PJ, Savickas ML, Walsh W, eds. APA handbook of career intervention, volume 1: foundations. Washington, DC: American Psychological Association, 2015: 81-98.

65 McKee-Ryan F, Song Z, Wanberg CR, et al. Psychological and physical well-being during unemployment: a meta-analytic study. $J$ Appl Psychol 2005;90:53-76.

66 Paul KI, Moser K. Incongruence as an explanation for the negative mental health effects of unemployment: meta-analytic evidence. $J$ Occup Organ Psychol 2006;79:595-621.

67 Kinderman P, Tai S, Pontin E, et al. Causal and mediating factors for anxiety, depression and well-being. Br J Psychiatry 2015;206:456-60.

68 Tarlov AR. Social determinants of health: the sociobiological translation. In: Blane D, Brunner E, Wilkinson RG, eds. Health and social organization: towards a health policy for the 21 st century. London, England: Routledge, 1996: 71-93.

69 Mayer R, Hamel C. La voix d'une population sans voix. Nouv Prat Soc 1996;9:151-68.

70 Raphael D, ed. Social determinants of health: Canadian perspectives. 2nd edn. Toronto, Canada: Canadian Scholars' Press, 2009.

71 Lechaume A, Savard F. Avis sur la mesure de l'exclusion sociale associée à la pauvreté: des indicateurs à suivre. Centre d'étude sur la pauvreté et l'exclusion, Gouvernement du Québec, 2015. Available: https://www.mtess.gouv.qc.ca/cepe/publications.asp [Accessed 15 Feb 2019]. 